\title{
Evaluation of potential reference genes for real-time qPCR analysis in a biparental beetle, Lethrus apterus (Coleoptera: Geotrupidae)
}

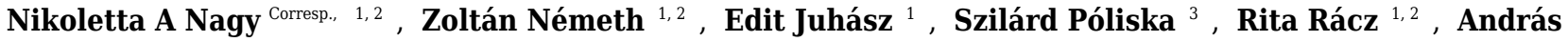 \\ Kosztolányi ${ }^{2,4}$, Zoltán Barta ${ }^{1,2}$ \\ 1 Department of Evolutionary Zoology, University of Debrecen, Debrecen, Hungary \\ ${ }^{3}$ Genomic Medicine and Bioinformatic Core Facility, Department of Biochemistry and Molecular Biology, Faculty of Medicine, University of Debrecen, \\ Debrecen, Hungary \\ 4 Department of Ecology, University of Veterinary Science, Budapest, Hungary \\ Corresponding Author: Nikoletta A Nagy \\ Email address: nnolett@gmail.com
}

Hormones play an important role in the regulation of physiological, developmental and behavioural processes. Many of these mechanisms in insects, however, are still not well understood. One way to investigate hormonal regulation is to analyse gene expression patterns of hormones and their receptors by real-time quantitative polymerase chain reaction (RT-qPCR). This method, however, requires stably expressed reference genes for normalisation. In the present study, we evaluated 11 candidate housekeeping genes as reference genes in samples of Lethrus apterus, an earth-boring beetle with biparental care, collected from a natural population. For identifying the most stable genes we used the following computational methods: geNorm, NormFinder, BestKeeper, comparative delta Ct method and RefFinder. Based on our results, the two body regions sampled (head and thorax) differ in which genes are most stably expressed. We identified two candidate reference genes for each region investigated: ribosomal protein L7A and RP18 in samples extracted from the head, and ribosomal protein L7A and RP4 extracted from the muscles of the thorax. Additionally, L7A and RP18 appear to be the best reference genes for normalisation in all samples irrespective of body region. These reference genes can be used to study the hormonal regulation of reproduction and parental care in Lethrus apterus in the future. 
1 Evaluation of potential reference genes for real-time qPCR analysis

2 in a biparental beetle, Lethrus apterus (Coleoptera: Geotrupidae)

3 Nikoletta A. Nagy ${ }^{1,2}$, Zoltán Németh ${ }^{1,2}$, Edit Juhász ${ }^{1}$, Szilárd Póliska ${ }^{3}$, Rita Rácz ${ }^{1,2}$, András

4 Kosztolányi ${ }^{2,4}$, Zoltán Barta ${ }^{1,2}$

$5{ }^{1}$ Department of Evolutionary Zoology and Human Biology, University of Debrecen, Debrecen,

6 Hungary

$7 \quad{ }^{2}$ MTA-DE Behavioural Ecology Research Group, Department of Evolutionary Zoology,

8 University of Debrecen, Debrecen, Hungary

$9{ }^{3}$ Genomic Medicine and Bioinformatic Core Facility, Department of Biochemistry and Molecular

10 Biology, Faculty of Medicine, University of Debrecen, Debrecen, Hungary

$11{ }^{4}$ Department of Ecology, University of Veterinary Science Budapest, Budapest, Hungary

12 Corresponding Author:

13 Nikoletta A. Nagy, MTA-DE Behavioural Ecology Research Group, Department of Evolutionary

14 Zoology, University of Debrecen, H-4032 Debrecen, Egyetem tér 1, Hungary. E-mail:

15 nnolett@gmail.com. Phone number: +36205253959. 


\section{Abstract}

17 Hormones play an important role in the regulation of physiological, developmental and

18 behavioural processes. Many of these mechanisms in insects, however, are still not well

19 understood. One way to investigate hormonal regulation is to analyse gene expression patterns of

20 hormones and their receptors by real-time quantitative polymerase chain reaction (RT-qPCR).

21 This method, however, requires stably expressed reference genes for normalisation. In the present

22 study, we evaluated 11 candidate housekeeping genes as reference genes in samples of Lethrus

23 apterus, an earth-boring beetle with biparental care, collected from a natural population. For

24 identifying the most stable genes we used the following computational methods: geNorm,

25 NormFinder, BestKeeper, comparative delta Ct method and RefFinder. Based on our results, the

26 two body regions sampled (head and thorax) differ in which genes are most stably expressed. We

27 identified two candidate reference genes for each region investigated: ribosomal protein L7A and

28 RP18 in samples extracted from the head, and ribosomal protein L7A and RP4 extracted from the

29 muscles of the thorax. Additionally, L7A and RP18 appear to be the best reference genes for

30 normalisation in all samples irrespective of body region. These reference genes can be used to

31 study the hormonal regulation of reproduction and parental care in Lethrus apterus in the future. 
Introduction

33 Hormonal regulation in insects generates great interest among entomologists but hormones have only been studied in detail in a few species (Gullan \& Cranston, 2014). Insect hormones of particular interest include juvenile hormones, ecdysteroids and neuropeptides. These molecules regulate a vast number of physiological and developmental processes as well as behaviours (Gäde, Hoffmann \& Spring, 1997). Studying these hormones used to be difficult considering their small amount and the occasional instability (Gullan \& Cranston, 2014). The technical revolution of molecular biology and genetics, however, made it attainable to discover the details of genetic and hormonal regulation in insects (Raikhel, Brown \& Belles, 2005). Some of the processes controlled by hormones mentioned above, such as ecdysis (Mykles et al., 2013) are already well described. Nevertheless, there are many other interesting physiological and behavioural mechanisms, like parental care, the hormonal regulation of which are not well understood (Panaitof et al., 2016). One way to increase our understanding of hormonal regulation is to identify patterns of gene expression associated with the hormones in question (Champagne \& Curley, 2012).

Real-time quantitative polymerase chain reaction (RT-qPCR) is a commonly used method for analysing gene expression as it is a sensitive, fast and reproducible method, moreover it requires only a minimal amount of RNA (Radonić et al., 2004). With this method, gene expression levels can be measured simultaneously in several different samples for a limited number of genes. Gene expression analyses with RT-qPCR, however, require some kind of normalisation in order to control the variation caused by stochastic processes occurring during the analytic procedure (Vandesompele et al., 2002). This normalisation is usually achieved by taking into account the expression level of so-called reference genes (VanGuilder, Vrana \& Freeman, 2008). These genes are usually selected from housekeeping genes, which produce proteins vital for maintaining fundamental cell functions, like ribosomal or cytoskeletal proteins. Therefore, the expression levels of these reference genes are thought to be relatively stable. Thus, comparing the expression level of genes of interest with the expression levels of the reference genes, we can eliminate the differences caused by the different amount and quality of starting material. With this method we are able to control for differences occurring due to technical errors during sample preparation as well (e.g. RNA isolation and cDNA synthesis, Radonić et al., 2004). Nonetheless, expression levels of the housekeeping genes may also vary considerably under certain circumstances 
63 because they can be involved in processes other than maintenance functions of the cell, e.g.

64 apoptosis (Nicholls, Li \& Liu, 2012), cytokinesis (D’Souza-Schorey \& Chavrier, 2006) and

65 development (Zhou et al., 2015). Therefore, a given housekeeping gene cannot automatically

66 serve as reference gene, and normalisation with unstable reference genes can lead to erroneous

67 quantification results and conclusions (Thellin et al., 1999). Consequently, reference genes must

68 be carefully selected so that their expression levels are similar between the different samples and

69 should not be influenced significantly by different experimental conditions (VanGuilder, Vrana

70 \& Freeman, 2008). According to Vandesompele et al. (2002), the combination of two or more

71 reference genes is highly recommended for normalisation to obtain more accurate results. In case

72 of multiple reference genes, it is advised to use the geometric mean for normalisation since it

73 better controls for extreme values and the possible differences between expression levels of the

74 different genes (Vandesompele et al., 2002).

75 Lethrus apterus (Laxmann, 1770) (Coleoptera: Geotrupidae) is an earth-boring beetle that has

76 biparental care during which the parents provision food for their offspring in advance their

77 hatching (Kosztolányi et al., 2015). This kind of parental care is a complex and relatively rare

78 trait among insects (Smiseth, Kölliker \& Royle, 2012) and makes this beetle an outstanding

79 model species for studying the hormonal background of parental care. In order to do so, however,

80 stably expressed reference genes have to be identified.

81 In recent years, numerous studies aimed to identify stable reference genes in insects (Lord et

82 al., 2010; Ponton et al., 2011; Bansal et al., 2012; Li et al., 2013; Pan et al., 2015; Yu et al.,

83 2016). Nevertheless, there is a lack of reference gene studies that use individuals from natural

84 populations. Our objective in this study was to examine the expression stability of several

85 housekeeping genes in Lethrus apterus across different times of the breeding period in a natural

86 population in order to identify the most stable reference gene(s). With the right combination of

87 reference genes, the expression levels of hormone regulating genes involved in parental care in

88 Lethrus apterus can be examined accurately in the future. Based on the literature (Shi et al., 2013;

89 Liang et al., 2014; Zhu et al., 2014; Yang et al., 2015), we probed eleven housekeeping genes.

90 Materials and methods

91 Sample collection 
92 Samples were collected near Dorogháza, northern Hungary $\left(47^{\circ} 59^{\prime} 29^{\prime \prime} \mathrm{N}, 19^{\circ} 53^{\prime} 36^{\prime \prime} \mathrm{E}\right)$ on $16^{\text {th }}$

93 April, $4^{\text {th }}$ May and $28^{\text {th }}$ May in 2015, which dates corresponded to the beginning, middle and end

94 of the breeding season of Lethrus apterus, respectively. Sample collection was approved by the

95 Nothern Hungarian Inspectorate for Environment Protection and Nature Conservation (No. 9007-

96 8/2014). The first sampling date represents the period of mate choice, while the second and third

97 samplings were done during the period when parents were collecting leaves for the offspring. On

98 each sampling dates head and thorax samples were collected from 8 males and 8 females. All

99 tissues were removed from the head capsule and muscle samples were taken from the thorax.

100 Samples were collected in the field in less than five minutes after euthanizing the individuals.

101 Each head and thorax sample was put immediately into separate eppendorf tubes which already

102 contained $600 \mu \mathrm{l}$ RNAlater ${ }^{\circledR}$ Stabilization Solution (Thermo Fisher Scientific, Waltham,

103 Massachusetts, USA), then stored at $-20{ }^{\circ} \mathrm{C}$ in the laboratory in order to inhibit RNase enzyme

104 activity until RNA extraction.

105 RNA extraction and cDNA synthesis

106 Total RNA was isolated from each samples using TRIzol® Reagent (Thermo Fisher Scientific,

107 Waltham, Massachusetts, USA) following the manufacturer's instructions. The extracted RNA

108 was eluted in 15-30 $\mu \mathrm{l}$ RNase-free water, depending on the pellet size. Yield of RNA was

109 quantified by NanoDrop 1000 Spectrophotometer (Thermo Fisher Scientific, Waltham,

110 Massachusetts, USA). To eliminate genomic DNA, samples were treated with RQ1 RNase-Free

111 DNase (Promega, Madison, Wisconsin, USA) just before the reverse transcription. First strand

112 cDNA was synthesized from $1 \mu \mathrm{g}$ DNA-free RNA using the High-Capacity cDNA Reverse

113 Transcription Kit (Applied Biosystems, Foster City, California, USA).

114 Reference gene selection and primer design

115 Using a draft genome of Lethrus apterus (unpublished data) eleven reference genes, which were

116 already described as stable reference genes in other arthropods, were selected (Table 1). We

117 manually designed primers (Table 2) using the web-based Sequence Manipulation Suite

118 (Stothard, 2000) and Multiple Primer Analyzer (Thermo Fisher Scientific, Waltham,

119 Massachusetts, USA) in order to avoid the forming of possible secondary structures of the

120 primers. To check the specificity of primer pairs and to determine optimal annealing temperature,

121 PCR reactions were performed in $10 \mu \mathrm{l}$ volumes containing the following components: 10x 
122 buffer, $2 \mathrm{mM} \mathrm{MgCl} 2,0.2 \mathrm{mM}$ dNTP, $0.02 \mathrm{U} / \mu \mathrm{L}$ Taq DNA polymerase enzymes (DreamTaq

123 Green, Thermo Fisher Scientific, Waltham, Massachusetts, USA), $0.2 \mu \mathrm{M}$ forward and $0.2 \mu \mathrm{M}$

124 reverse primer and $0.1 \mu \mathrm{g}$ cDNA. PCR conditions were optimized by determining the optimal

125 annealing temperature using temperature gradient ranging from $54^{\circ} \mathrm{C}$ to $62^{\circ} \mathrm{C}$ for primer binding.

126 In this study, we used ABI Veriti ${ }^{\circledR}$ 96-Well Thermal Cycler (Applied Biosystems, Foster City,

127 California, USA). Cycling conditions consisted of a denaturing step at $95^{\circ} \mathrm{C}$ for 2 min followed

128 by 40 cycles at $95^{\circ} \mathrm{C}$ for $30 \mathrm{sec}$, at a temperature gradient $\left(54^{\circ} \mathrm{C}, 56^{\circ} \mathrm{C}, 58^{\circ} \mathrm{C}, 60^{\circ} \mathrm{C}\right.$ or $\left.62^{\circ} \mathrm{C}\right)$ for

$12930 \mathrm{sec}$ and at $72^{\circ} \mathrm{C}$ for $90 \mathrm{sec}$, and finally at $72^{\circ} \mathrm{C}$ for $10 \mathrm{~min}$. PCR amplicons were run on $1 \%$

130 agarose gel stained with GelRed ${ }^{\mathrm{TM}}$ (Biotium, Fremont, California, USA).

131 Real-time quantitative PCR

132 RT-qPCR was performed on a QuantStudio 12K Flex Real-Time PCR System (Applied

133 Biosystems, Foster City, California, USA) using SYBR® Green PCR Master Mix (Applied

134 Biosystems, Foster City, California, USA) and ROX Passive Reference Dye (Affymetrix, Santa

135 Clara, California, USA). Amplifications were carried out under the following conditions: initial

136 denaturation at $95^{\circ} \mathrm{C}$ for $10 \mathrm{~min}$ followed by 40 cycles of $10 \mathrm{sec}$ at $95^{\circ} \mathrm{C}$ and for $1 \mathrm{~min}$ at the

137 optimal annealing temperature. This was followed by a melting curve analysis in which the

138 temperature raised from $65^{\circ} \mathrm{C}$ to $95^{\circ} \mathrm{C}$ in sequential steps of $0.05^{\circ} \mathrm{C}$ for 1 second. Three technical

139 replicates were performed for each biological sample, and the average cycle threshold $(\mathrm{Ct})$ values

140 of triplicates were calculated. Furthermore, no-template control was done in order to check

141 whether primer-dimers or contamination with amplified PCR product were detectable. Five 5-

142 fold serial dilution was made from cDNA samples to create a standard curve, and the

143 amplification efficiency was determined for each candidate gene. The efficiency (E) values were

144 calculated according to the equation: $E=\left(10^{(-1 / \text { slope })}-1\right) \times 100$, where slope is the slope of the standard

145 curve (Radonić et al., 2004).

146 Statistical analysis of raw $\mathrm{Ct}$ values

147 In order to examine the differences between sample groups, random intercept mixed-effects

148 models were used with sample id as a random factor for each gene. Significance of fixed terms

149 was investigated by likelihood ratio tests. For likelihood ratio tests models were fitted using

150 Maximum Likelihood estimation. The analyses were carried out using "Ime4" (Bates et al., 2014) 
151 and "car" (Fox \& Weisberg, 2011) packages in the R statistical environment version 3.3.2 (R

152 Core Team 2016).

153 Determination of reference gene expression stability

154 In order to determine the expression stability of the selected reference genes, we used the 155 following methods: geNorm (Vandesompele et al., 2002), NormFinder (Andersen, Jensen \& 156 Ørntoft, 2004), BestKeeper (Pfaffl et al., 2004), delta Ct method (Silver et al., 2006) and

157 RefFinder (Xie et al., 2012). For the analyses with the geNorm and NormFinder procedures, the

158 average $\mathrm{Ct}$ values were transformed to relative quantities by dividing sample values by the lowest

159 average $\mathrm{Ct}$ value. For calculations by BestKeeper, delta $\mathrm{Ct}$ method and RefFinder, the

160 untransformed average Ct values were used. All calculations, except the ones done by the web-

161 based RefFinder, were carried out in R with "NormqPCR” package (Perkins et al., 2012).

162 geNorm calculates the expression stability value $\mathrm{M}$ by assessing the mean pairwise expression

163 ratio for each candidate gene against all the other candidates (Vandesompele et al., 2002). The

164 basic assumption of this method is that the expression ratio between two reference genes is

165 identical across the samples. The lower the $M$ value the more stable the expression of the

166 candidate reference gene. Stepwise exclusion of the genes with the highest $M$ value results in the

167 selection of the two most stably expressed reference genes in the tested samples both sharing the

168 same M value. Vandesompele et al. (2002) also suggest not to accept candidate genes as stably

169 expressed reference genes with $\mathrm{M}$ value higher than 1.5. Moreover, the procedure determines the

170 normalisation factor by taking the geometric mean of the expression levels from the most stable

171 genes and then additively recalculating with each of the next most stable gene. The pairwise

172 variation, $\mathrm{V}_{\mathrm{n} / \mathrm{n}+1}$ between two sequential normalisation factors is then calculated in order to

173 determine the effect of each newly added gene to the normalisation factor. The optimum number

174 of genes is the lowest number of genes with $\mathrm{V}_{\mathrm{n} / \mathrm{n}+1}$ less than 0.15 (Vandesompele et al., 2002).

175 NormFinder determines the stability of the candidate reference genes by measuring the intra-

176 and intergroup variation between user specified groups (e.g. male and female groups or treated

177 and control groups) first. Stability values for each candidate gene are then calculated by adding

178 the two sources of variation. The lowest stability value means the most stable expression

179 (Andersen, Jensen \& Ørntoft, 2004). 
180 BestKeeper calculates, for each candidate reference gene across the samples, the geometric 181 mean, the arithmetic mean, the minimal and the maximal $\mathrm{Ct}$ values, in addition to the average 182 absolute deviation from the arithmetic mean. Genes with the lowest average absolute deviation 183 can be considered as stably expressed reference genes. BestKeeper Index is calculated as the 184 geometric mean of the $\mathrm{Ct}$ values of the candidate reference genes. Inter-gene relations are 185 estimated by performing pairwise correlation analyses of all possible reference gene pairs. 186 Furthermore, correlation between the expression level of each candidate gene and the BestKeeper 187 Index is calculated, describing the relation between the index and the contributing genes by the 188 Pearson correlation coefficient, coefficient of determination and the corresponding p-value (Pfaffl 189 et al., 2004).

190 The delta $\mathrm{Ct}$ method compares relative expression of pairs of candidate genes within each 191 sample in order to identify the stably expressed housekeeping genes. If the $\Delta \mathrm{Ct}$ value of the two 192 genes fluctuates when analysed in different samples, it means that one or both genes are variably expressed. If the $\Delta \mathrm{Ct}$ value remains constant, both genes are stably expressed among the samples

194 (Silver et al., 2006).

195 Each procedure mentioned above uses different algorithms to calculate an expression stability 196 value which represents the suitability of the candidate genes as reference genes, therefore the 197 ranking of the examined genes according to the methods may vary. The web-based tool

198 RefFinder [1] was used in order to combine our results and rank the candidate genes. This user199 friendly program integrates the four methods mentioned above. Using the ranking from each 200 program, it assigns an appropriate weight to an individual gene and calculates the geometric 201 mean of their weights for the overall ranking. The lowest rank indicates the most stably expressed 202 gene (Xie et al., 2012).

203 For each analysis, except for NormFinder, seven sample groups were used: all samples 204 irrespective of body part or sex; head samples irrespective of sex; male head samples; female 205 head samples; thorax samples irrespective of sex; male thorax samples; female thorax samples. 206 The calculation by NormFinder requires subgroup specification, therefore, body regions were set 207 as subgroups for the analysis of all samples. In order to investigate the effect of sexes, male and 208 female subgroups were specified for the analysis of head and thorax sample groups separately. In 209 this way, three sample groups, each divided into two subgroups, were analysed by NormFinder. 


\section{Results}

211 Transcriptional profiling of candidate reference genes

212 Before the evaluation of expression stability of the eleven candidate genes, specificity of each

213 primer pair was checked on 1\% agarose gel which showed single products with the expected

214 sizes. Moreover, gene-specific amplification was confirmed by single melting curve peaks. These

215 results indicate that no primer-dimers or nonspecific amplification products were formed.

216 Additionally, no fluorescent signals were detected in the negative control during the RT-qPCR.

217 Each amplicons were sequenced and annotated to the sequences from which the primer design

218 was based in order to check that the correct genes were amplified. The sequences are available in

219 Supplemental file 1. The efficiency of the eleven candidate genes ranged from 99.33 to $112.70 \%$.

220 The efficiency values and other basic information of the RT-qPCR required based on the

221 guideline of Bustin et al. are included in Table 2 (Bustin et al. 2009).

222 Raw Ct values ranged from 11.66 (TUB1a) to 30.12 (ARF4) (Figure 1). The mean and

223 standard deviation (SD) of the Ct values across all samples were calculated for each gene (Table

224 3). Since the mean $\mathrm{Ct}$ values ranged between 15 and 30 for all the candidate reference genes, all

225 of them were analysed further (Kozera \& Rapacz, 2013). ARF1 had the least variable expression

226 level with the lowest $\mathrm{SD}$ value ( $\mathrm{SD}=1.85)$, while ARF4 had the most variable expression level

227 ( $\mathrm{SD}=3.04)$. Low average $\mathrm{Ct}$ values indicate high expression level in TUB1a and EF2

$228\left(\mathrm{Ct}_{\text {mean }}=15.11\right)$, on the other hand, high $\mathrm{Ct}$ values of $\mathrm{ARF} 1\left(\mathrm{Ct}_{\text {mean }}=20.77\right)$ indicated low

229 expression.

230 Based on the likelihood ratio tests, sex had no significant effect on the expression level of the

231 candidate genes. However, significant effect of body region was found in case of six genes:

232 GAPDH, EF1a, ARF1, ARF4, RP4 and L10. The interaction of sex and bodypart had no

233 significant effect on the expression level of the candidates, except for RPS8 (Table 4).

234 Expression stability of candidate reference genes

235 Based on geNorm analysis for all samples, eight candidate genes had an M value below the

236 threshold of 1.5 (Table S1). The results show that the lowest M value was 0.390 for RPS8 and

237 L7A. Among the head samples irrespective of sex, all of the tested genes except L10 had an M

238 value below 1.5, and RPS8 and RP18 were co-ranked as the most stable genes from the

239 candidates $(M=0.304)$. Furthermore, the same two genes had the lowest $M$ value considering 
240 male and female head samples separately ( $M=0.264$ for females and $M=0.346$ for males). In case

241 of the thorax samples irrespective of sex, eight genes had an M value below the threshold. RPS8

242 and L7A were the most stable candidate gene pair with an M value of 0.358 . In thorax samples

243 collected from females, RPS8 and RP18 were the most stable genes as well with an M value of

244 0.222. However, in thorax samples of males, RPS8 and L7A were ranked as the best reference

245 gene pair $(M=0.288)$.

246 According to NormFinder, L7A was the most stable gene when calculating with all samples

247 divided into groups of head and thorax samples (Table S2). The second and third genes were RP4

248 and RPS8, indicating that these are also worth considering as reference genes. In the case of

249 specifying males and females as subgroups within head and thorax samples, L7A was found

250 again to be the most stably expressed gene among the candidate ones. In both head and thorax

251 samples, L7A was followed by similar ranking order: EF2, RP4, RP18 and RPS8 as second,

252 third, fourth and fifth genes, respectively.

253 Based on BestKeeper, across all samples ARF1 had the lowest mean absolute deviation

254 (MAD) value, however, L7A had the highest correlation $r$ value (Table S3). In the group of head

255 samples irrespective of sex, ARF1 had the lowest MAD value, while among the thorax samples

256 irrespective of sex, L10 was the most stable according to the MAD value. This was surprising as

257 the other programs ranked this gene consistently as one of the least stable genes. On the other

258 hand, in both head and thorax samples, L7A had the highest $r$ value. In head samples of males

259 RPS8 (MAD=0.827), and of females ARF1 (MAD=1.122) were the most stable candidate genes.

260 In both male and female head samples, L7A had the highest correlation $r$ value. Considering male

261 thorax samples L10 had the lowest MAD value (MAD=1.576), while in female thorax samples

262 EF2 was ranked as the most stable with MAD value 1.236. L7A had the highest $r$ value in female

263 thorax samples, however, in male thorax samples EF2 had the highest correlation $r$ value.

264 According to the delta $\mathrm{Ct}$ method, L7A was the most stable gene among the candidates overall

265 with the stability value always below 1.0 (Table S4).

266 Finally, the candidate genes were evaluated by RefFinder to combine the results of individual

267 methods (Table 5). Using all samples irrespective of body region and sex, and separately the head

268 and thorax samples irrespective of sex, L7A was ranked first, as the most stably expressed gene

269 among the candidate reference genes. In head samples, RP18 was co-ranked with L7A as the

270 most stable reference genes. In thorax samples, RP4 was ranked on the second place. In female 
271 head and thorax samples, RP18 was the most stably expressed gene of the candidates.

272 Considering head samples of males, RPS8 was ranked on the first place, while in thorax samples

273 of males, L7A was ranked as the best reference gene. L7A was ranked on the second place in all

274 subgroups, with the exception of male thorax samples, where EF2 was the second best reference

275 gene according to RefFinder.

276 Optimal number of reference genes

277 To determine the minimal number of genes necessary for normalisation, the V-value was

278 computed by geNorm. The results demonstrated that across all samples $V_{2 / 3}$ was the first V-value

279 lower than the cut-off value of 0.15 (Figure 2). Considering separately the head and thorax

280 samples, $\mathrm{V}_{2 / 3}$ was again lower than 0.15 . Separate analyses of female and male samples within

281 head and thorax groups showed that $V_{2 / 3}$ was also the first value below the threshold in all cases

282 (results not shown). Therefore, two stably expressed reference genes are sufficient for

283 normalisation in any case of sample classification.

\section{Discussion}

285 RT-qPCR is a widely used method for measuring gene expression levels due to its relatively low 286 cost, high accuracy and sensitivity. A critical step of this method is data normalisation which

287 requires careful selection of reference genes for the given experimental or environmental

288 conditions. With these stably expressed genes, technical errors and variance resulting from the

289 method can be moderated (Udvardi, Czechowski \& Scheible, 2008). Several studies have

290 examined the stability of reference genes in various insect species in the past decade and these

291 studies suggest that no universally stable reference gene can be found that is applicable for all

292 species, tissue types and experimental conditions. Hence, it is necessary to identify the most

293 suitable reference genes for the specific circumstances in a given study for a given species (Zhu

294 et al., 2014).

295 In the present study, variation in expression levels of eleven housekeeping genes were

296 evaluated across a span of 1.5 months covering most of the breeding period of the biparental

297 beetle Lethrus apterus. To date, no study investigated the possible reference genes either in this

298 species, or in the family of Geotrupidae. We analyzed the expression stability of the candidate

299 reference genes by four frequently used programs: geNorm, NormFinder, BestKeeper and 
300 comparative delta $\mathrm{Ct}$ method. The outcomes of these programs can vary because of the

301 differences in the algorithms. Therefore, the combined use of them ensures more reliable results.

302 For this purpose, RefFinder, a freely available web-based tool was used to calculate a

303 comprehensive ranking value for each candidate gene.

304 According to the comprehensive ranking by RefFinder, the most stably expressed reference

305 gene was L7A across all samples, irrespective of body region and sex. Based on the results of

306 geNorm analysis, two reference genes are sufficient for normalisation in gene expression analysis

307 in Lethrus apterus during the breeding period. For accurate normalisation, we recommend the use

308 of L7A and RP18 in head samples irrespective of sex. When considering the sexes separately,

309 RPS8 and L7A should be used for head samples of males, and RP18 and L7A for females. In

310 thorax samples irrespective of sex, L7A and RP4 are the best reference genes. In case of thorax

311 samples, L7A and EF2 are recommended for normalisation in males, RP18 and L7A in females.

312 Consistent with our results, ribosomal proteins are reported to be the best reference genes in

313 many insect species. In a study by Zhu et al. (2014), ribosomal protein L7A was ranked as one of

314 the best reference genes in Spodoptera exigua in different tissues, specific larval physiological

315 stages and male individuals. Studies of other coleopterans gave similar results: RP4 and RP18

316 were the best reference genes in Leptinotarsa decemlineata (Shi et al., 2013), RPS3 (ribosomal

317 protein S3), RPL13a (ribosomal protein 13a) and RPS18 (ribosomal protein S18) were suitable

318 reference genes for Tribolium castaneum (Lord et al., 2010; Sang et al., 2015), and RPL22e

319 (ribosomal protein 22e) was one of the best reference genes in Mylabris cichorii both in males

320 and females (Wang et al., 2014). In other species, e.g. in Drosophila melanogaster Rpl32

321 (ribosomal protein L32) was a suitable reference gene in individuals on different diets (Ponton et

322 al., 2011), and in Aphis craccivora, RPS8, RPL14 (ribosomal protein L14), and RPL11

323 (ribosomal protein L11) were the three most stable housekeeping genes across different

324 developmental stages and temperature conditions (Yang et al., 2015).

325 Interestingly, two frequently used reference genes, GAPDH and TUB1a were ranked as less

326 stable genes in this study, beside ARF4, with stability values above the threshold values of all the

327 programs used. L10 was also found to be an unstable candidate gene in all but the geNorm

328 analysis. These results correspond with the findings of Thellin et al. (1999), i.e. housekeeping

329 genes should be evaluated as reference genes across the given experimental conditions in the

330 given species. Based on our results, we recommend to avoid the use of these last four genes for 
331 normalisation in studies investigating gene expression patterns during the reproductive period in

332 this species.

\section{Conclusion}

334 By evaluating the stability of eleven candidate housekeeping genes in samples collected during 335 the breeding period of free-living Lethrus apterus, we conclude that two of them provide 336 sufficient reference for normalising target gene expression. In head samples, these two genes 337 appear to be L7A and RP18, whereas in thorax samples L7A and RP4 should be used. In both 338 thorax and head samples of females, RP18 and L7A are the best choices for normalisation. Based 339 on our results, in head samples of males, RPS8 and L7A, while in thorax samples of males, L7A 340 and EF2 are recommended to use. These results provide reliable reference genes that are suitable 341 normalizers for further RT-qPCR investigations on the hormonal regulation in Lethrus apterus.

\section{Acknowledgements}

343 We are grateful to Tamás Varga for allowing us to conduct fieldwork on his property and Adrien 344 Fónagy for helping us in the development of the autopsy.

\section{References}

Andersen CL., Jensen JL., Ørntoft TF. 2004. Normalization of Real Time Quantitative Reverse Transcription PCR Data: A Model Based Variance Estimation Approach to Identify Genes

Bansal R., Mamidala P., Mian RMA., Mittapalli O., Michel AP. 2012. Validation of Reference Genes for Gene Expression Studies in Aphis glycines (Hemiptera: Aphididae). Journal of Economic Entomology 105:1432-1438. DOI: 10.1603/EC12095.

Bustin, SA., Benes, V., Garson, JA., Hellemans, J., Huggett, J., Kubista, M., Mueller R., Tolan, T., Pfaffl, MW., Shipley, GL., Vandesompele, J., Wittwer, CT. (2009). The MIQE Guidelines: Minimum Information for Publication of Quantitative Real-Time PCR Experiments. Clinical chemistry 55:611-622. DOI: 10.1373/clinchem.2008.112797. 
359 Champagne FA., Curley JP. 2012. Genetics and Epigenetics of Parental Care. In: Royle NJ.,

360 Smiseth PT., Kölliker M. eds. The Evolution of Parental Care. Oxford: Oxford University

361 Press, 304-326.

362 D'Souza-Schorey C., Chavrier P. 2006. ARF proteins: roles in membrane traffic and beyond.

363 Nature Reviews Molecular Cell Biology 7:347-358. DOI: 10.1038/nrm1910.

364 Fox J., Weisberg S. 2011. An R Companion to Applied Regression. Thousand Oaks CA: Sage $365 \quad$ Publications.

366 Gäde G., Hoffmann K-H., Spring JH. 1997. Hormonal regulation in insects: facts, gaps, and 367 future directions. Physiological reviews 77:963-1032.

368 Gullan PJ., Cranston PS. 2014. The Insects: An Outline of Entomology. John Wiley \& Sons, Ltd.

369 Kosztolányi A., Nagy N., Kovács T., Barta Z. 2015. Predominant female care in the beetle

$370 \quad$ Lethrus apterus with supposedly biparental care. Entomological Science 18:292-294. DOI:

$371 \quad$ 10.1111/ens.12123.

372 Kozera B., Rapacz M. 2013. Reference genes in real-time PCR. Journal of Applied Genetics 54:391-406. DOI: 10.1007/s13353-013-0173-x.

Liang P., Guo Y., Zhou X., Gao X. 2014. Expression profiling in Bemisia tabaci under insecticide treatment: Indicating the necessity for custom reference gene selection. PLoS ONE 9:1-8. DOI: 10.1371/journal.pone.0087514.

Li R., Xie W., Wang S., Wu Q., Yang N., Yang X., Pan H., Zhou X., Bai L., Xu B., Zhou X., Zhang Y. 2013. Reference Gene Selection for qRT-PCR Analysis in the Sweetpotato Whitefly, Bemisia tabaci (Hemiptera: Aleyrodidae). PLoS ONE 8:1-8. DOI: 10.1371/journal.pone.0053006.

Lord JC., Hartzer K., Toutges M., Oppert B. 2010. Evaluation of quantitative PCR reference genes for gene expression studies in Tribolium castaneum after fungal challenge. Journal of Microbiological Methods 80:219-221. DOI: 10.1016/j.mimet.2009.12.007.

Mykles DL., Adams ME., Gäde G., Lange AB., Marco HG., Orchard I. 2013. Neuropeptide action in insects and crustaceans. Physiological and Biochemical Zoology 83:836-846. DOI: 10.1086/648470.Neuropeptide.

Nicholls C., Li H., Liu JP. 2012. GAPDH: A common enzyme with uncommon functions. Clinical and Experimental Pharmacology and Physiology 39:674-679. DOI: 10.1111/j.1440-1681.2011.05599.x.

Panaitof SC., Yaeger JDW., Speer JP., Renner KJ. 2016. Biparental behavior in the burying beetle Nicrophorus orbicollis: A role for dopamine? Current Zoology 62:285-291. DOI: 10.1093/cz/zow032. 
393

394

395

396

397

398

399

400

401

402

403

404

405

406

407

408

409

410

411

412

413

414

415

416

417

418

419

420

421

422

423

424

425

426

Pan H., Yang X., Siegfried BD., Zhou X. 2015. A comprehensive selection of reference genes for RT-qPCR analysis in a predatory lady beetle, Hippodamia convergens (Coleoptera: Coccinellidae). PLoS ONE 10:1-15. DOI: 10.1371/journal.pone.0125868.

Perkins JR., Dawes JM., McMahon SB., Bennett DL., Orengo C., Kohl M. 2012. ReadqPCR and NormqPCR: R packages for the reading, quality checking and normalisation of RT-qPCR quantification cycle (Cq) data. BMC Genomics 13:296. DOI: 10.1186/1471-2164-13-296.

Pfaffl MW., Tichopad A., Prgomet C., Neuvians TP. 2004. Determination of stable housekeeping genes, differentially regulated target genes and sample integrity: BestKeeper--Excel-based tool using pair-wise correlations. Biotechnology letters 26:509-515. DOI: 10.1023/B:BILE.0000019559.84305.47.

Ponton F., Chapuis MP., Pernice M., Sword GA., Simpson SJ. 2011. Evaluation of potential reference genes for reverse transcription-qPCR studies of physiological responses in Drosophila melanogaster. Journal of Insect Physiology 57:840-850. DOI: 10.1016/j.jinsphys.2011.03.014.

Radonić A., Thulke S., Mackay IM., Landt O., Siegert W., Nitsche A. 2004. Guideline to reference gene selection for quantitative real-time PCR. Biochemical and Biophysical Research Communications 313:856-862. DOI: 10.1016/j.bbrc.2003.11.177.

Raikhel AS., Brown MR., Belles X. 2005. Hormonal Control of Reproductive Processes. In: Gilbert LI., Iatrou K., Gill SS. eds. Comprehensive Molecular Insect Science. Oxford: Elsevier, 433-491.

Sang W., He L., Wang X-P., Zhu-Salzman K., Lei C-L. 2015. Evaluation of Reference Genes for RT-qPCR in Tribolium castaneum (Coleoptera: Tenebrionidae) under UVB Stress. Environmental Entomology 44:418-425. DOI: 10.1093/ee/nvv010.

Shi X-Q., Guo W-C., Wan P-J., Zhou L-T., Ren X-L., Ahmat T., Fu K-Y., Li G-Q. 2013. Validation of reference genes for expression analysis by quantitative real-time PCR in Leptinotarsa decemlineata (Say). BMC Research Notes 6:93. DOI: 10.1186/1756-0500-693.

Silver N., Best S., Jiang J., Thein SL. 2006. Selection of housekeeping genes for gene expression studies in human reticulocytes using real-time PCR. BMC Molecular Biology 7:33. DOI: 10.1186/1471-2199-7-33.

Smiseth PT., Kölliker M., Royle NJ. 2012. What is Parental Care? In: Royle NJ., Smiseth PT., Kölliker M. eds. The Evolution of Parental Care. Oxford: Oxford University Press, 1-20.

Stothard P. 2000. The Sequence Manipulation Suite: JavaScript Programs for Analyzing and Formatting Protein and DNA Sequences. BioTechniques 28:1102, 1104. 
427 Thellin O., Zorzi W., Lakaye B., De Borman B., Coumans B., Hennen G., Grisar T., Igout A., 428 Heinen E. 1999. Housekeeping genes as internal standards: Use and limits. Journal of Biotechnology 75:291-295. DOI: 10.1016/S0168-1656(99)00163-7.

Udvardi MK., Czechowski T., Scheible W-R. 2008. Eleven Golden Rules of Quantitative RTPCR. The Plant Cell 20:1736-1737. DOI: 10.1105/tpc.108.061143.

Vandesompele J., De Preter K., Pattyn F., Poppe B., Van Roy N., De Paepe A., Speleman F. 2002. Accurate normalization of real-time quantitative RT-PCR data by geometric averaging of multiple internal control genes. Genome biology 3:1-11. DOI: 10.1186/gb-2002-3-7research0034.

VanGuilder HD., Vrana KE., Freeman WM. 2008. Twenty-five years of quantitative PCR for gene expression analysis. BioTechniques 44:619-626. DOI: 10.2144/000112776.

Wang Y., Wang Z., Huang Y., Liao Y., Yin Y. 2014. Identification of suitable reference genes for gene expression studies by qRT-PCR in the blister beetle Mylabris cichorii. Journal of Insect Science 14:1-10.

Xie F., Xiao P., Chen D., Xu L., Zhang B. 2012. miRDeepFinder: A miRNA analysis tool for deep sequencing of plant small RNAs. Plant Molecular Biology 80:75-84. DOI: 10.1007/s11103-012-9885-2.

Yang C., Pan H., Liu Y., Zhou X. 2015. Temperature and development impacts on housekeeping gene expression in cowpea aphid, Aphis craccivora (Hemiptera: Aphidiae). PLoS ONE 10:1-10. DOI: 10.1371/journal.pone.0130593.

Yu S-H., Yang P., Sun T., Qi Q., Wang X-Q., Xu D-L., Chen X-M. 2016. Identification and evaluation of reference genes in the Chinese white wax scale insect Ericerus pela. SpringerPlus 5:791. DOI: 10.1186/s40064-016-2548-z.

Zhou X., Liao WJ., Liao JM., Liao P., Lu H. 2015. Ribosomal proteins: Functions beyond the ribosome. Journal of Molecular Cell Biology 7:92-104. DOI: 10.1093/jmcb/mjv014.

Zhu X., Yuan M., Shakeel M., Zhang Y., Wang S., Wang X., Zhan S., Kang T., Li J. 2014. Selection and evaluation of reference genes for expression analysis using qRT-PCR in the beet armyworm Spodoptera exigua (Hübner) (Lepidoptera: Noctuidae). PLoS ONE 9:1-14. DOI: 10.1371/journal.pone.0084730. 


\section{Table 1 (on next page)}

The list of the candidate housekeeping genes with their biological functions. 


\begin{tabular}{|c|c|c|c|}
\hline & & & \\
\hline $\begin{array}{l}\text { glyceraldehyde 3-phosphate } \\
\text { dehydrogenase }\end{array}$ & GAPDH & glycolytic enzyme & Liang et al. 2014 \\
\hline tubulin alpha-1 chain & TUB1a & $\begin{array}{l}\text { cytoskeletal structural } \\
\text { protein }\end{array}$ & Liang et al. 2014 \\
\hline elongation factor 1-alpha & EF1a & protein synthesis & Liang et al. 2014 \\
\hline elongation factor 2 & $\mathrm{EF} 2$ & protein synthesis & Zhu et al. 2014 \\
\hline $\begin{array}{l}\text { ADP-ribosylation factor-like } \\
\text { protein } 1\end{array}$ & ARF1 & GTP-binding protein & Shi et al. 2013 \\
\hline ADP-ribosylation factor 4 & ARF4 & GTP-binding protein & Shi et al. 2013 \\
\hline ribosomal protein $\mathrm{S} 8$ & RPS8 & $\begin{array}{l}\text { structural constituent of } \\
\text { ribosome }\end{array}$ & Yang et al. 2015 \\
\hline ribosomal protein L4 & RP4 & $\begin{array}{l}\text { structural constituent of } \\
\text { ribosome }\end{array}$ & Shi et al. 2013 \\
\hline ribosomal protein L7A & L7A & $\begin{array}{l}\text { structural constituent of } \\
\text { ribosome }\end{array}$ & Zhu et al. 2014 \\
\hline ribosomal protein L10 & L10 & $\begin{array}{l}\text { structural constituent of } \\
\text { ribosome }\end{array}$ & Zhu et al. 2014 \\
\hline ribosomal protein L18 & RP18 & $\begin{array}{l}\text { structural constituent of } \\
\text { ribosome }\end{array}$ & Shi et al. 2013 \\
\hline
\end{tabular}




\section{Table 2 (on next page)}

The primers used to measure gene expression levels for the candidate reference genes by RT-qPCR.

${ }^{a} \mathrm{~F}$ : forward primer; R: reverse primer

${ }^{b}$ melting temperature

creal-time qPCR efficiency (calculated by the standard curve method)

${ }^{d}$ regression coefficient (calculated from the regression line of the standard curve) 


\begin{tabular}{|c|c|c|c|c|c|c|}
\hline Gene & $\begin{array}{l}\text { GenBank accession } \\
\text { number }\end{array}$ & Primer sequence $\left(5^{\prime} \text { to } 3\right)^{a}$ & $\begin{array}{l}\text { Amplicon } \\
\text { length (bp) }\end{array}$ & $\begin{array}{l}\mathbf{T m} \\
\left({ }^{\circ} \mathbf{C}\right)^{b}\end{array}$ & $\mathbf{E}(\%)^{c}$ & $\mathbf{R}^{2 d}$ \\
\hline \multirow[t]{2}{*}{ GAPDH } & KY786279 & F: GCCATTCCAGTAAGTTTTCCATTGAG & 157 & 85.0 & 100.75 & 0.91 \\
\hline & & R: GCTGTTACTGCTACACAAAAGAC & & & & \\
\hline \multirow[t]{2}{*}{ TUB1a } & KY786273 & F: CAGACTGCACGTTGGACTTTAGC & 172 & 83.6 & 100.04 & 0.96 \\
\hline & & R: TACAGAGGAGATGTTGTCCCCAAG & & & & \\
\hline \multirow[t]{2}{*}{ EF1a } & KY786281 & F: AAACCTTTGCGTCTTCCACTACAGG & 184 & 81.7 & 99.83 & 0.94 \\
\hline & & R: CTTCAGTTGTAAGACCAACAGGTG & & & & \\
\hline \multirow[t]{2}{*}{ EF2 } & KY786280 & F: GATGAGAAATCCACATGTCCAG & 244 & 82.0 & 102.00 & 0.86 \\
\hline & & R: CGACTCCCTAGTATCAAAGG & & & & \\
\hline \multirow[t]{2}{*}{ ARF1 } & KY786283 & F: GTATGACAGTAGCTGAAGTTC & 141 & 81.4 & 112.70 & 0.84 \\
\hline & & R: CTGTTTTGTAAAGCATTGGC & & & & \\
\hline \multirow[t]{2}{*}{ ARF4 } & KY786282 & F: TAGTACGGACGGTCAAGTC & 197 & 89.1 & 105.91 & 0.81 \\
\hline & & R: GTAGACCGTCACCTGTTATGGC & & & & \\
\hline \multirow[t]{2}{*}{ RPS8 } & KY786274 & F: CATTATGTACGTACGAGAGGAGGCAACG & 200 & 84.0 & 99.96 & 0.91 \\
\hline & & R: TCTAAAGGGAGTAGCGTCGATAACG & & & & \\
\hline \multirow[t]{2}{*}{ RP4 } & KY786275 & F: TAATGGACCACGACGCTGTATGC & 248 & 84.5 & 100.33 & 0.92 \\
\hline & & R: CGTACCAGCTTTAGTAATGAGCAAGG & & & & \\
\hline \multirow[t]{2}{*}{ L7A } & KY786277 & F: TAGCGACTCAACTGTTCAAGG & 224 & 84.8 & 99.54 & 0.95 \\
\hline & & R: CCTCAATTGGATCGACGTCATGTG & & & & \\
\hline \multirow[t]{2}{*}{ L10 } & KY786278 & F: CGTAGAGCCTCGATAACTTGG & 210 & 84.7 & 99.33 & 0.94 \\
\hline & & R: TCATGTGCTGGAGCTGATAGG & & & & \\
\hline \multirow[t]{2}{*}{ RP18 } & KY786276 & F: TTGTAACCACATGAACGCCTACG & 186 & 85.2 & 99.75 & 0.96 \\
\hline & & R: AGTTAGCTTTACGTTCACCTACTGG & & & & \\
\hline
\end{tabular}




\section{Table 3(on next page)}

Mean, standard deviation and coefficient of variation for the $\mathrm{Ct}$ values of 11 candidate reference genes, calculated across all samples. 


$\begin{array}{llll}\text { Genes } & \text { Mean } & \text { SD } & \text { CV } \\ \text { GAPDH } & 15.27 & 2.62 & 0.17157826 \\ \text { TUB1a } & 15.11 & 2.64 & 0.17471873 \\ \text { EF1a } & 15.44 & 2.34 & 0.1515544 \\ \text { EF2 } & 15.11 & 2.05 & 0.13567174 \\ \text { ARF1 } & 20.77 & 1.85 & 0.08907078 \\ \text { ARF4 } & 20.22 & 3.04 & 0.15034619 \\ \text { RPS8 } & 16.38 & 2.12 & 0.12942613 \\ \text { RP4 } & 15.52 & 1.94 & 0.125 \\ \text { L7A } & 17.27 & 2.1 & 0.12159815 \\ \text { L10 } & 16.15 & 1.97 & 0.12198142 \\ \text { RP18 } & 16.02 & 1.93 & 0.12047441\end{array}$




\section{Table 4 (on next page)}

Results of likelihood ratio tests on the effects of body region, sex and their interaction on the expression levels of the eleven candidate reference genes.

Significant effects are highlighted in bold. 


\begin{tabular}{lllllll} 
Gene & Sex & & Bodypart & \multicolumn{3}{c}{ Sex*Bodypart } \\
& $\chi^{2}$ & $\mathbf{P}$ & $\chi^{\mathbf{2}}$ & $\mathbf{P}$ & $\chi^{\mathbf{2}}$ & $\mathbf{P}$ \\
GAPDH & 0.019 & 0.889 & $\mathbf{5 . 6 6 8}$ & $\mathbf{0 . 0 1 7}$ & 0.965 & 0.326 \\
TUB1a & 0.642 & 0.423 & 1.960 & 0.162 & 1.995 & 0.158 \\
EF1a & 0.002 & 0.968 & $\mathbf{4 . 0 9 6}$ & $\mathbf{0 . 0 4 3}$ & 0.857 & 0.355 \\
EF2 & 1.216 & 0.270 & 2.271 & 0.132 & 2.030 & 0.154 \\
ARF1 & 0.476 & 0.490 & $\mathbf{4 . 1 4 7}$ & $\mathbf{0 . 0 4 2}$ & 2.459 & 0.117 \\
ARF4 & 1.417 & 0.234 & $\mathbf{4 . 8 8 5}$ & $\mathbf{0 . 0 2 7}$ & 1.289 & 0.256 \\
RPS8 & 0.586 & 0.444 & 2.307 & 0.129 & $\mathbf{4 . 0 0 7}$ & $\mathbf{0 . 0 4 5}$ \\
RP4 & 0.356 & 0.551 & $\mathbf{4 . 2 7 2}$ & $\mathbf{0 . 0 3 9}$ & 2.384 & 0.127 \\
L7A & 0.556 & 0.456 & 3.087 & 0.079 & 2.901 & 0.089 \\
L10 & 0.246 & 0.620 & $\mathbf{8 . 5 0 9}$ & $\mathbf{0 . 0 0 4}$ & 3.319 & 0.068 \\
RP18 & 1.028 & 0.311 & 2.336 & 0.126 & 2.896 & 0.089
\end{tabular}




\section{Table 5 (on next page)}

Stability ranking of the eleven candidate reference genes in the different sample groups as calculated by RefFinder. 


\begin{tabular}{|c|c|c|c|c|c|c|c|}
\hline \multirow[t]{2}{*}{ Rank } & \multirow{2}{*}{$\begin{array}{l}\text { All } \\
\text { samples }\end{array}$} & \multicolumn{3}{|c|}{ Head samples } & \multicolumn{3}{|c|}{ Thorax samples } \\
\hline & & $\begin{array}{l}\text { All head } \\
\text { samples }\end{array}$ & $\begin{array}{l}\text { Male head } \\
\text { samples }\end{array}$ & $\begin{array}{l}\text { Female } \\
\text { head } \\
\text { samples }\end{array}$ & $\begin{array}{l}\text { All thorax } \\
\text { samples }\end{array}$ & $\begin{array}{l}\text { Male } \\
\text { thorax } \\
\text { samples }\end{array}$ & $\begin{array}{l}\text { Female } \\
\text { thorax } \\
\text { samples }\end{array}$ \\
\hline 1 & L7A & L7A & RPS8 & RP18 & L7A & L7A & RP18 \\
\hline 2 & RP18 & RP18 & L7A & L7A & RP4 & $\mathrm{EF} 2$ & L7A \\
\hline 3 & RPS8 & RPS8 & RP18 & RPS8 & RP18 & RPS8 & $\mathrm{EF} 2$ \\
\hline 4 & $\mathrm{EF} 2$ & ARF1 & $\mathrm{EF} 2$ & $\mathrm{EF} 2$ & RPS8 & RP4 & RPS8 \\
\hline 5 & ARF1 & RP4 & TUB1a & ARF1 & $\mathrm{EF} 2$ & L10 & RP4 \\
\hline 6 & RP4 & $\mathrm{EF} 2$ & RP4 & RP4 & L10 & EF1a & L10 \\
\hline 7 & EF1a & GAPDH & ARF1 & EF1a & ARF1 & RP18 & ARF1 \\
\hline 8 & TUB1a & TUB1a & GAPDH & GAPDH & EF1a & ARF1 & EF1a \\
\hline 9 & L10 & EF1a & L10 & ARF4 & TUB1a & ARF4 & TUB1a \\
\hline 10 & GAPDH & L10 & ARF4 & L10 & ARF4 & TUB1a & GAPDH \\
\hline 11 & ARF4 & ARF4 & EF1a & TUB1a & GAPDH & GAPDH & ARF4 \\
\hline
\end{tabular}


Figure 1

Expression profiles of the 11 candidate reference genes.

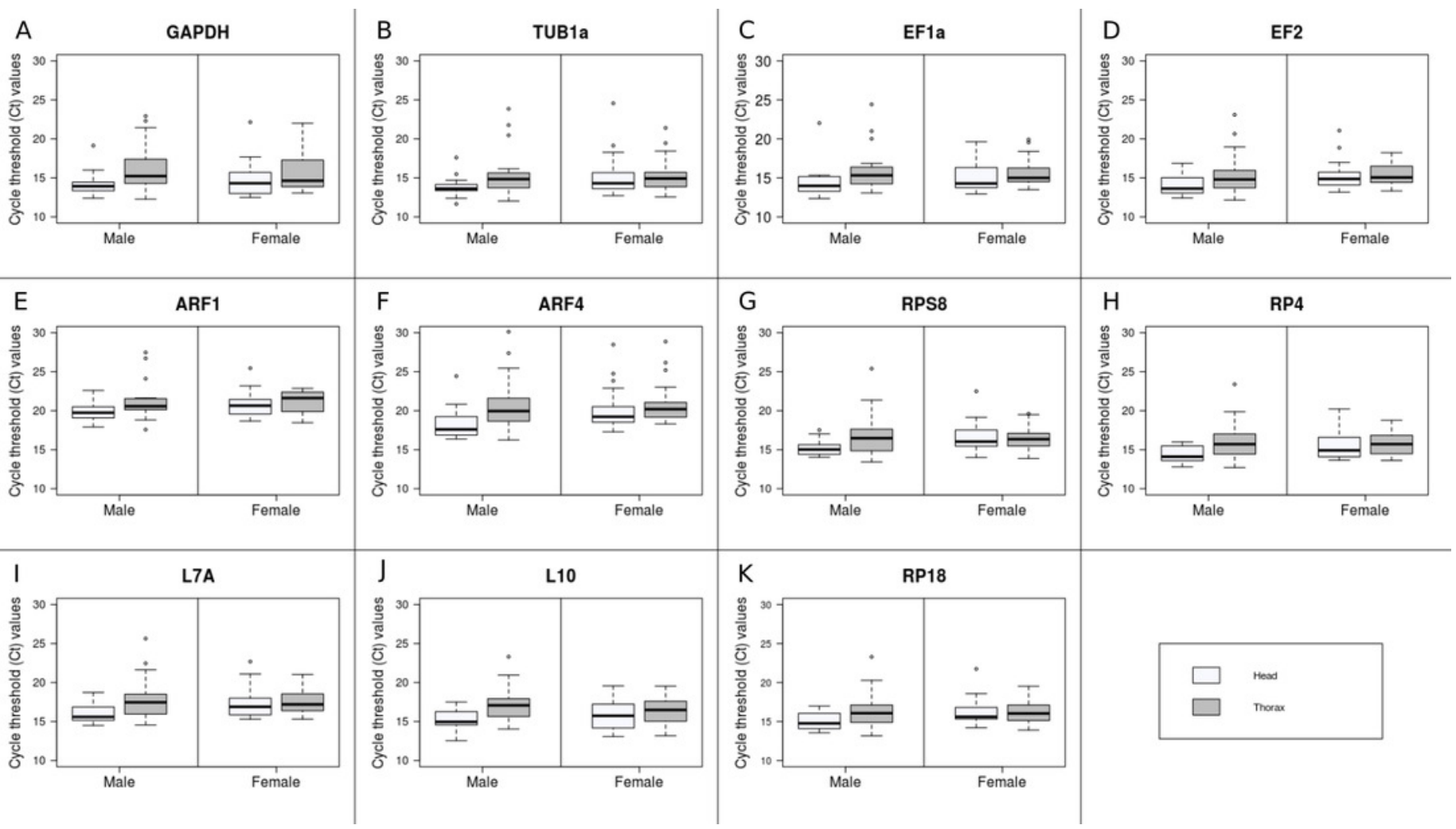




\section{Figure 2}

Pairwise variation analyses by geNorm to determine the optimal number of reference genes for accurate normalization.

Pairwise variation for all samples together, as well as separately for head and thorax samples. The lowest number of genes with $\mathrm{V}_{\mathrm{n} / \mathrm{n+1}}$ less than 0.15 means the optimum number of genes.

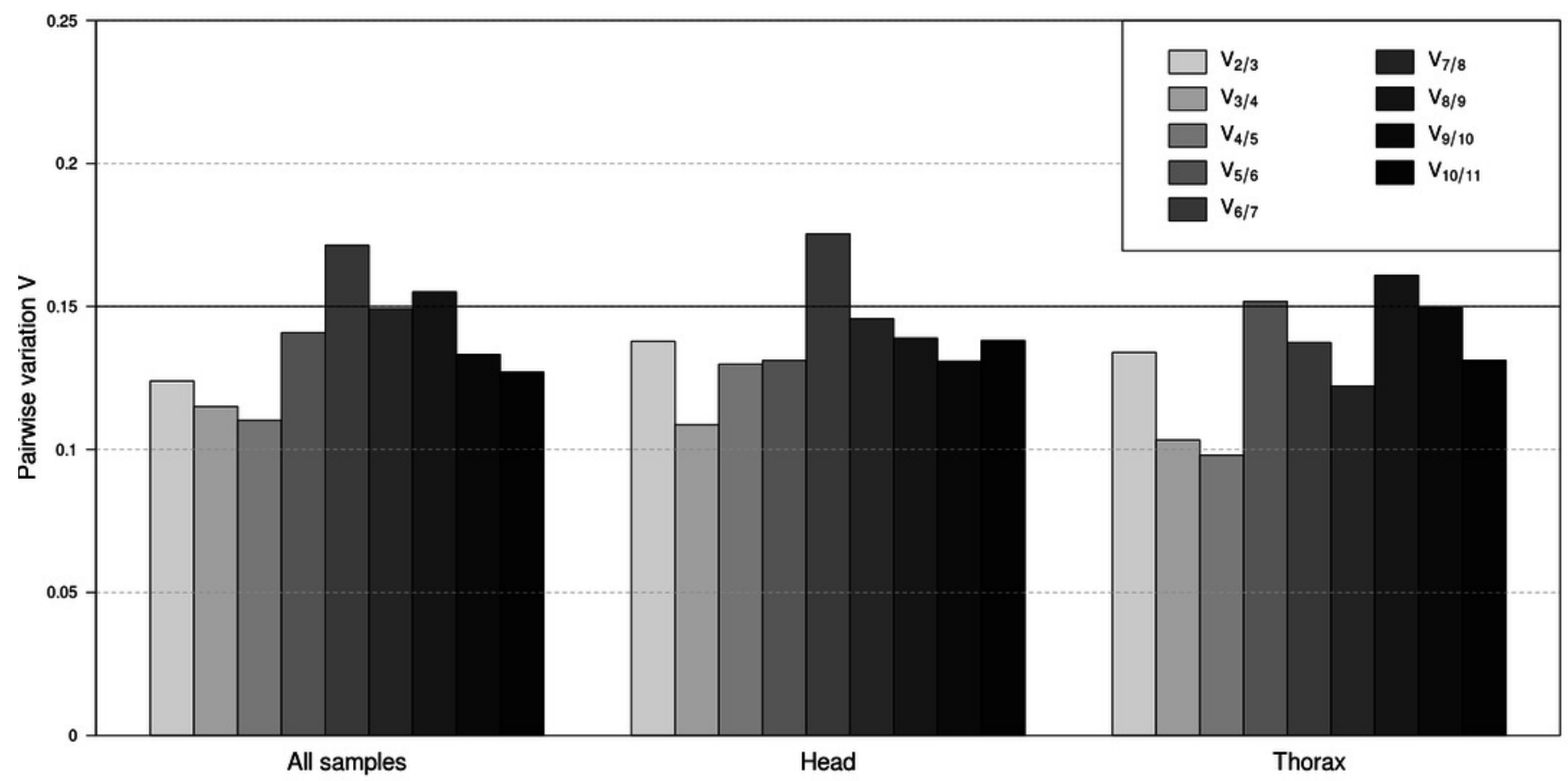

